\title{
Искусственные подложки GaAs/Si(001), выращенные методом молекулярно-лучевой эпитаксии, для оптоэлектронных приложений
}

М.О. Петрушков ${ }^{1}$, Е.А. Емельянов ${ }^{1}$, М.А. Путято ${ }^{1}$, А.В. Васев ${ }^{1}$, А.К. Бакаров ${ }^{1}$, А.К. Гутаковский ${ }^{1}$, О.С. Комков ${ }^{2}$, Д.Д. Фирсов ${ }^{2}$, Д.С. Абрамкин ${ }^{1}$, В.В. Преображенский ${ }^{1}$

${ }^{1}$ ИФП СО РАН, Новосибирск, 630090, пр. ак. Лаврентьева, 13

2 ЛЭТИ, Санкт-Петербург, 197376, ул. Профессора Попова, 5 тел: +7 (383) 333-1967, факс:+7 (383)333-7745, эл.nочта: maikdi@isp.nsc.ru

DOI 10.34077/RCSP2021-40

Интеграция кремниевой электроники и светоизлучающей элементной базы на основе соединений $\mathrm{A}^{\mathrm{III}} \mathrm{B}^{\mathrm{V}}$ открывает перспективу значительного ускорения обработки информации за счёт передачи данных по оптическому каналу как в пределах одного процессора, так и между различными устройствами [1]. Наиболее перспективной гетеропарой в ряду $\mathrm{A}^{\mathrm{III}} \mathrm{B}^{\mathrm{V}} / \mathrm{Si}$ является система $\mathrm{GaAs} / \mathrm{Si}$, позволяющая надеется на использование уже разработанных оптоэлектронных излучателей на основе GaAs гетероструктур.

Из-за несоответствия постоянных решёток и коэффициентов температурного линейного расширения Si и GaAs в эпитаксиальных пленках образуется большая плотность пронизывающих дислокаций (ПД), которые ухудшают оптические и электрофизические свойства гетероструктур. В данной работе с целью снижения ПД использовались дислокационные фильтры на основе слоев низкотемпературного GaAs (LT-GaAs), выращенных при $250^{\circ} \mathrm{C}$. Также проводились in situ циклические отжиги эпитаксиальных структур на различных этапах их выращивания и ex situ отжиги уже выращенных образцов. Температура отжигов составляла $650^{\circ} \mathrm{C}$, что всего на $50^{\circ} \mathrm{C}$ превышает температуру роста GaAs. Определены условия, при которых совместное применение дислокационных фильтров на основе LT-GaAs и циклических отжигов позволяет снизить плотность ПД в приповерхностных слоях $\mathrm{GaAs}$ до $5 \cdot 10^{6} \mathrm{~cm}^{-2}$, а концентрацию центров безызлучательной рекомбинации до уровня, сравнимого с гомоэпитаксиальными структурами $\mathrm{GaAs}$ при общей толщине слоев $\mathrm{GaAs} / \mathrm{Si}$ до 2.4 мкм [2].

Полученные данные позволяют заключить, что применение дислокационных фильтров на основе слоев LT-GaAs является эффективным по следующим причинам. Во-первых, это наличие механических напряжений в системе LT-GaAs/GaAs из-за присутствия избыточного мышьяка в слоях LT-GaAs [3]. Эти напряжения способствуют изгибанию пронизывающих дислокаций и формированию дислокаций несоответствия на границе LT-GaAs/GaAs, аналогично действию напряжённых сверхрешёток [4]. Во-вторых, LT-GaAs является ограниченным источником вакансий галлия [5], которые диффундируют в высокотемпературные слои GaAs и облегчают скольжение ПД как в

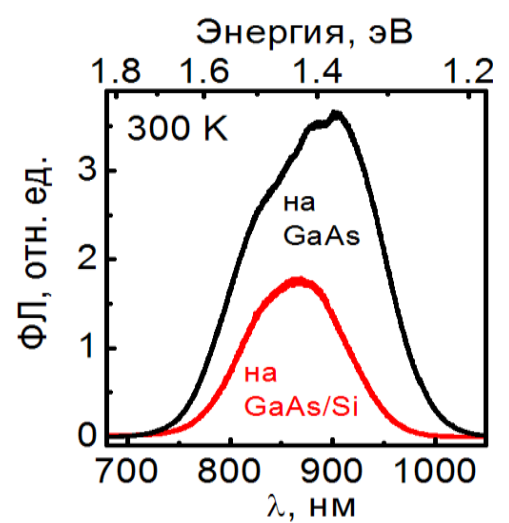

Рис. 1. Спектры люминесценции структур с InAs/AlAs KT, выращенных на различных подложках. процессе эпитаксии, так и в процессе циклических отжигов. Так, сопоставление данных просвечивающей электронной микроскопии и фотолюминесценции для структур $\mathrm{GaAs} / \mathrm{Si}$, подвергшихся in situ циклическому отжигу на различных этапах их выращивания, показало, что повышенное содержание вакансий $\mathrm{Ga}$ в высокотемпературных слоях $\mathrm{GaAs}$ ведёт к снижению плотности ПД в приповерхностных слоях гетероструктуры.

Полученные GaAs/Si структуры были использованы как искусственные подложки для роста гетероструктур с InAs/AlAs КТ. Гетероструктуры с КТ характеризуются люминесценцией при комнатной температуре в диапазоне длин волн 800-950 нм, сопоставимой по эффективности с аналогичными структурами, выращенными на согласованных $\mathrm{GaAs}$ подложках (рис. 1). Таким образом, продемонстрировано, что получаемые нами искусственные $\mathrm{GaAs} / \mathrm{Si}$ подложки пригодны для выращивания на них светоизлучающих $\mathrm{A}^{\mathrm{III}} \mathrm{B}^{\mathrm{V}}$ гетероструктур.

\section{Лumepamypa}

[1] Chen Sun et. al., Nature 528, 534 (2015);

[2] Д. С. Абрамкин и др. Автометрия 54, 85 (2018);

[3] C.C. Phua et. al., Jpn. J. Appl. Phys. 33, L405 (1994);

[4] M. Yamaguchi et. al., Appl. Phys. Lett. 542568 (1989);

[5] Isao Ohbu et. al., Jpn. J. Appl. Phys. 31 L1647 (1992). 